\title{
Expression of LRIG1 is associated with good prognosis and human papillomavirus status in oropharyngeal cancer
}

\author{
D Lindquist ${ }^{\star}, 1$, A Näsman ${ }^{2}, \mathrm{M}$ Tarján ${ }^{3}$, R Henriksson ${ }^{1}, \mathrm{~T}$ Tot $^{3}, \mathrm{~T}$ Dalianis ${ }^{2}$ and H Hedman ${ }^{1}$ \\ ${ }^{1}$ Department of Radiation Sciences, Umeå University, SE-901 87, Umeå, Sweden; ${ }^{2}$ Department of Oncology-Pathology, Karolinska \\ Institute, SE-171 76, Stockholm, Sweden and ${ }^{3}$ Department of Pathology and Clinical Cytology, Central Hospital Falun, SE-791 29, \\ Falun, Sweden
}

Background: The incidence of human papillomavirus (HPV)-associated oropharyngeal cancer has increased rapidly during the past decades. HPV is typically associated with a favourable outcome; however, a need exists for new and more effective prognostic and predictive markers for this disease. Leucine-rich repeats and immunoglobulin-like domains (LRIG)-1 is a tumour suppressor protein that belongs to the LRIG family. LRIG1 expression has prognostic significance in various human cancers, including cervical cancer, where HPV is a key aetiological agent.

Methods: The prognostic value of LRIG1 and LRIG2 immunoreactivity was investigated in tumour specimens from a Swedish cohort of patients with tonsillar and base of tongue oropharyngeal cancers, including 278 patients.

Results: LRIG1 immunoreactivity correlated with disease-free survival and overall survival in univariate and multivariate analyses. Notably, patients with HPV-positive tumours with high LRIG1 staining intensity or a high percentage of LRIG1-positive cells showed a very good prognosis. Furthermore, LRIG1 expression correlated with HPV status, whereas LRIG2 expression inversely correlated with HPV status.

Conclusions: Taken together, the results suggest that LRIG1 immunoreactivity could be a clinically important prognostic marker in HPV-associated oropharyngeal cancer.

Cancers of the oropharynx and hypopharynx resulted in an estimated 135000 new cases and 95000 deaths worldwide in 2008 (Ferlay et al, 2010). The majority of these cancers originate from the oropharynx, and tonsillar and base of tongue cancers are the two most common oropharyngeal cancer subtypes. Human papillomavirus (HPV) DNA is present in $50-90 \%$ of all oropharyngeal cancers (Hammarstedt et al, 2006; Nasman et al, 2009; Attner et al, 2010), and it is a positive prognostic factor in these cancers (Mellin et al, 2004; Lindstrom et al, 2007; Attner et al, 2011). The incidence of oropharyngeal cancer has been increasing recently (Hammarstedt et al, 2006; Attner et al, 2010), and it has been suggested that this increase is due to an increased incidence of HPV-positive tonsillar and base of tongue cancers (Hammarstedt et al, 2006; Nasman et al, 2009; Ramqvist and Dalianis, 2010; Attner et al, 2011).
Oropharyngeal cancer, irrespective of HPV status, is often treated with induction chemotherapy, intensified hyperfractionated radiotherapy, and the epidermal growth factor (EGF) receptor (EGFR) antibody cetuximab at advanced stages (Pignon et al, 2009; Bonner et al, 2010). However, it is largely unknown which patients benefit from the respective treatments. Therefore, new and more effective prognostic and predictive markers are needed.

The human leucine-rich repeats and immunoglobulin-like domains (LRIG) gene family includes three genes: LRIG1, LRIG2, and LRIG3 (Nilsson et al, 2001; Guo et al, 2004; Holmlund et al, 2004). Recently, Lrig1 was shown to function as a tumour suppressor in the mouse intestine (Powell et al, 2012), and increasing evidence indicates that LRIG1 may function as a tumour suppressor in humans (reviewed in Hedman and Henriksson, 2007 and Wang et al, 2013). Molecular studies have shown that LRIG1 
inhibits tyrosine kinase receptors of the EGFR family, MET, and RET (Gur et al, 2004; Laederich et al, 2004; Shattuck et al, 2007; Ledda et al, 2008). In certain cancer cells, high expression of LRIG1 is associated with increased sensitivity to platinum-based and other cytostatic drugs (Stutz et al, 2008; Li et al, 2011; Wu et al, 2011). It has been reported that LRIG1 ectodomains can be shed and suppress EGF signalling in co-cultured cells, suggesting that LRIG1 ectodomains can suppress proliferation by acting in a paracrine manner (Yi et al, 2011). This non-cell autonomous inhibition of growth factor receptor signalling was recently exploited for the treatment of experimental glioma in mice (Johansson et al, 2013). Furthermore, high LRIG1 RNA or protein expression correlates with a longer survival in breast cancer (Krig et al, 2011), cervical cancer (Lindstrom et al, 2008; Muller et al, 2013), nasopharyngeal cancer (Sheu et al, 2014), and cutaneous squamous cell carcinoma (Tanemura et al, 2005). In prostate cancer, the association between LRIG1 expression and patient survival seems to be contextdependent (Thomasson et al, 2011). In patients with cervical adenocarcinoma, expression of both LRIG1 and LRIG3 is associated with increased survival, and there is also an association between LRIG1 and LRIG3 expression and HPV status in these tumours (Muller et al, 2013). Expression of LRIG proteins and the clinical implications in oropharyngeal cancer have, to our knowledge, not been previously studied.

Here, we investigated the expression of LRIG proteins by immunohistochemistry in 278 tonsillar and base of tongue tumours, and analysed the possible correlations between LRIG expression and HPV status and patient survival.

\section{MATERIALS AND METHODS}

Patients and materials. The patient cohort included 290 patients treated at the Karolinska University Hospital, Sweden, between 2000 and 2007 and has been presented in detail in a previous study (Nasman et al, 2013). Clinical data were collected from patient files, including TNM stage, tumour localisation, time of relapse, treatment, and cause of death. In this cohort, tumour material consisted of the whole diagnostic specimen from each patient, and the survival end points were disease-free survival and overall survival.

Detection of HPV DNA. Analysis of HPV status in these patient samples has been described previously (Mellin et al, 2002; Lindquist et al, 2012). Briefly, DNA was extracted from a 10$\mu \mathrm{m}$-thick section of the paraffin-embedded diagnostic biopsy, and polymerase chain reaction was used to amplify the L1 and E1 regions of the HPV genome. HPV type was determined by using HPV16 type-specific primers or Multiplex Luminex. Negative controls were included in all analyses and between all samples to detect and avoid cross-contamination. 225 of 290 (78\%) tumours were HPV-positive (Nasman et al, 2013). Most of the tumours carrying HPV were infected with HPV16 (Nasman et al, 2013).

Immunohistochemistry of the LRIG proteins, p16INK4a, and CD44. The immunohistochemical staining protocols for the LRIG proteins have previously been described in detail (Nilsson et al, 2003; Holmlund et al, 2004; Guo et al, 2006). In the present study, the LRIG1-151 antibody was further validated by immunohistochemical staining of formaldehyde-fixed and paraffin-embedded pellets of H1975 cells that expressed endogenous levels of LRIG1 or H1975 ${ }^{\text {DoxLRIG1 }}$ cells that overexpressed a doxycycline-regulated LRIG1 transgene (Supplementary Figure S1). The intensity and percentage of positive cells were evaluated by a senior pathologist (MT). The intensity was evaluated on a four-grade semiquantitative scale as absent, weak, intermediate, or strong (Figure 1A-D), and each level was defined based on the majority of the staining. The fraction of positive cells was evaluated and scored as no staining or $1-25 \%, 26-50 \%, 51-75 \%$, or $76-100 \%$ positive cells (Figure 1E-H). The immunohistochemical staining results for p16INK4a and CD44 have been published previously (Nasman et al, 2013). p16INK4a staining was considered positive when strong and highly prevalent (more than $76 \%$ positive cells), and CD44 was evaluated in semi-quantitative four grade scales as presented in Table 1 (Nasman et al, 2013).

Statistical analyses. The association between ordinal variables was tested using either a $\chi^{2}$-test or Fisher's exact test where suitable. Significance testing was performed at the 0.05 level, and only twosided $P$-values were presented. Overall survival with expression of the different LRIG proteins as a grouping factor was illustrated in a Kaplan-Meier graph, and a log-rank test was used to compare the groups. All significant differences in the univariate analyses and factors generally known to influence survival were then included in a Cox regression multivariate analysis to evaluate the possible independent influence on the risk of mortality for each factor.

\section{RESULTS}

LRIG protein expression and clinical features. We performed the present immunohistochemical study to evaluate the prognostic significance of LRIG protein expression in oropharyngeal cancer. Detailed characteristics of the patient cohort have been presented
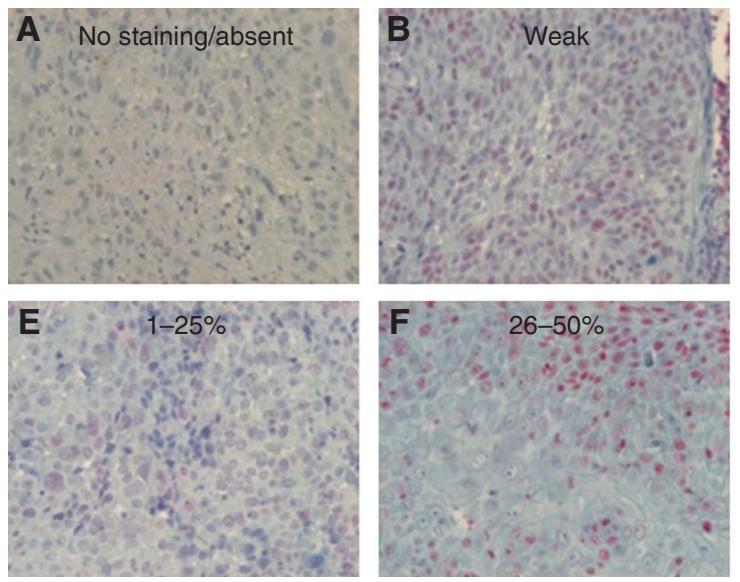
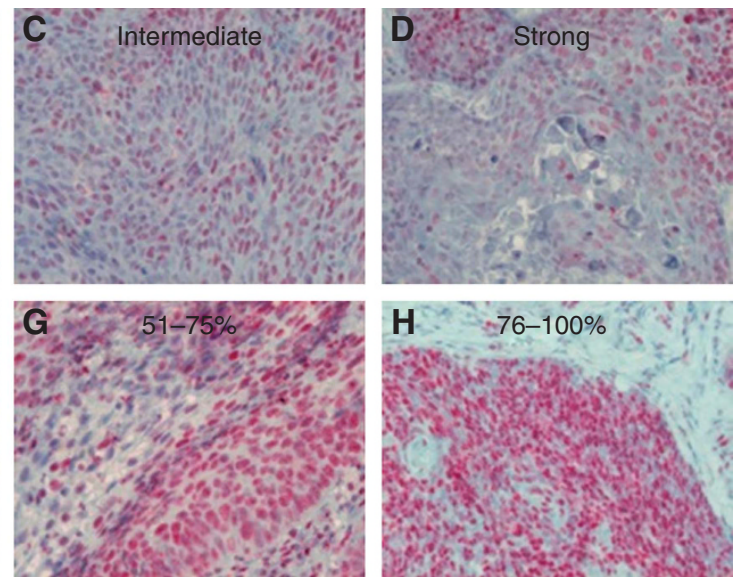

Figure 1. Examples of oropharyngeal cancers immunostained for LRIG1. Various LRIG1 staining intensities are exemplified in the upper row (A-D), and various percentages of LRIG1-positive cells are exemplified in the lower row (E-H). 


\section{Table 1. Correlations between LRIG1 staining intensity and the percentage of positive cells and various clinical and molecular parameters}

\begin{tabular}{|c|c|c|c|c|c|c|}
\hline & \multicolumn{3}{|c|}{ LRIG1 intensity } & \multicolumn{3}{|c|}{ LRIG1 expression } \\
\hline & Absent (\%) & Present (\%) & $P$-value & $0-25 \%, n(\%)$ & $26-100 \%, n(\%)$ & $P$-value \\
\hline \multicolumn{7}{|l|}{ Localisation } \\
\hline $\begin{array}{l}\text { Base of tongue } \\
\text { Tonsil }\end{array}$ & $\begin{array}{c}7(9) \\
27(13)\end{array}$ & $\begin{array}{r}70(91) \\
174(87)\end{array}$ & ns & $\begin{array}{l}26(34) \\
58(29)\end{array}$ & $\begin{array}{r}51(66) \\
143(71)\end{array}$ & ns \\
\hline \multicolumn{7}{|l|}{ Sex } \\
\hline $\begin{array}{l}\text { Female } \\
\text { Male }\end{array}$ & $\begin{array}{l}13(18) \\
21(10)\end{array}$ & $\begin{array}{r}59(82) \\
185(90)\end{array}$ & ns & $\begin{array}{l}28(39) \\
56(27)\end{array}$ & $\begin{array}{r}44(61) \\
150(73)\end{array}$ & ns \\
\hline \multicolumn{7}{|l|}{ Stage } \\
\hline $\begin{array}{l}I+I I \\
I I I+I V\end{array}$ & $\begin{array}{r}6(20) \\
28(11)\end{array}$ & $\begin{array}{r}24(80) \\
220(89)\end{array}$ & ns & $\begin{array}{l}11(37) \\
73(29)\end{array}$ & $\begin{array}{r}19(63) \\
175(71)\end{array}$ & ns \\
\hline \multicolumn{7}{|c|}{ CD44 intensity } \\
\hline $\begin{array}{l}\text { Absent } \\
\text { Weak } \\
\text { Medium } \\
\text { Strong }\end{array}$ & $\begin{array}{c}2(9) \\
5(9) \\
7(10) \\
20(15)\end{array}$ & $\begin{array}{r}19(91) \\
52(91) \\
62(90) \\
111(85)\end{array}$ & ns & $\begin{array}{r}5(24) \\
14(25) \\
16(23) \\
49(37)\end{array}$ & $\begin{array}{l}16(76) \\
43(75) \\
53(77) \\
82(63)\end{array}$ & ns \\
\hline \multicolumn{7}{|c|}{ CD44 expression } \\
\hline $\begin{array}{l}\text { Absent } \\
1-25 \% \\
26-75 \% \\
76-100 \%\end{array}$ & $\begin{array}{c}2(9) \\
1(3) \\
9(18) \\
22(12)\end{array}$ & $\begin{array}{r}19(91) \\
29(97) \\
40(82) \\
156(88)\end{array}$ & ns & $\begin{array}{r}5(24) \\
6(20) \\
13(27) \\
60(34)\end{array}$ & $\begin{array}{r}16(76) \\
24(80) \\
36(73) \\
118(66)\end{array}$ & ns \\
\hline \multicolumn{7}{|l|}{ HPV status } \\
\hline $\begin{array}{l}\text { Negative } \\
\text { Positive }\end{array}$ & $\begin{array}{l}13(21) \\
21(10)\end{array}$ & $\begin{array}{r}50(79) \\
194(90)\end{array}$ & 0.021 & $\begin{array}{l}29(46) \\
55(26)\end{array}$ & $\begin{array}{r}34(54) \\
160(74)\end{array}$ & 0.002 \\
\hline \multicolumn{7}{|l|}{ p16INK4a } \\
\hline $\begin{array}{l}\text { Negative } \\
\text { Positive }\end{array}$ & $\begin{array}{l}17(23) \\
17(8)\end{array}$ & $\begin{array}{r}56(77) \\
188(92)\end{array}$ & 0.001 & $\begin{array}{l}37(51) \\
47(23)\end{array}$ & $\begin{array}{r}36(49) \\
158(77)\end{array}$ & $<0.0001$ \\
\hline
\end{tabular}

previously (Nasman et al, 2013). Initially, a smaller patient series was stained for LRIG1, LRIG2, and LRIG3. LRIG3 staining was deemed to be of insufficient quality for meaningful interpretation, and was therefore not further studied in the present report. Therefore, the cohort was stained for LRIG1 and LRIG2 only. In the cohort of 290 patients, both the intensity and percentage of positive cells were evaluated in 278 patients for LRIG1 (Figure 1), and 275 patients for LRIG2; some patients were excluded because of limited tumour material. Patient and tumour characteristics in relation to HPV status did not differ compared with previous reports when excluding these patients (Nasman et al, 2013; data not shown).

LRIG1 staining was negative in 34 (12\%) of the tumours, and LRIG1 staining intensity was weak in $119(43 \%)$, intermediate in $98(35 \%)$, and strong in $27(10 \%) ; 50(18 \%)$ of the tumours had 1-25\% LRIG1-positive cells, 65 (23\%) had $26-50 \%$ positive cells, $95(34 \%)$ had $51-75 \%$ positive cells, and 34 (12\%) had $76-100 \%$ positive cells. LRIG2 staining was negative in 21 (8\%) of the tumours, and LRIG2 staining intensity was weak in $160(58 \%)$ of the tumours, intermediate in $82(30 \%)$, and strong in $12(4 \%)$; $74(27 \%)$ of the tumours had 1-25\% LRIG2-positive cells, 86 (31\%) had $26-50 \%$ positive cells, 85 (31\%) had $51-75 \%$ positive cells, and $9(3 \%)$ had $76-100 \%$ positive cells. There was no correlation between LRIG1 or LRIG2 expression and patient age, tumour stage, sex, or tumour site (Table 1, data not shown for LRIG2).

Correlation between LRIG protein expression and CD44 expression, p16 expression, and HPV status. Both the intensity of LRIG1 staining and the percentage of LRIG1-positive cells correlated with HPV status and p16INK4a status, but no correlation with either the intensity of CD44 staining or the percentage of CD44-positive cells was found (Table 1). For LRIG2, the intensity of staining but not the percentage of positive cells was inversely correlated with p16INK4a status $\left(P<0.0001, \chi^{2}\right.$-test $)$ and HPV status $\left(P<0.0001, \chi^{2}\right.$-test). No correlation between LRIG2 expression and CD44 staining intensity or the percentage of positive cells was found (data not shown).

LRIG1 and LRIG2 protein expression, HPV status, and patient survival. Both the intensity of LRIG1 staining and the percentage of positive cells correlated with disease-free survival and overall survival (Figures 2 and 3, respectively). The patients were dichotomised into two groups, where intensity of staining was scored as either absent or present (including weak, intermediate, and strong intensity of staining) and the percentage of positive cells was scored as either $0-25 \%$ or $26-100 \%$ positive cells. The intensity of LRIG1 staining and the percentage of LRIG1-positive cells correlated with both disease-free survival and overall survival 

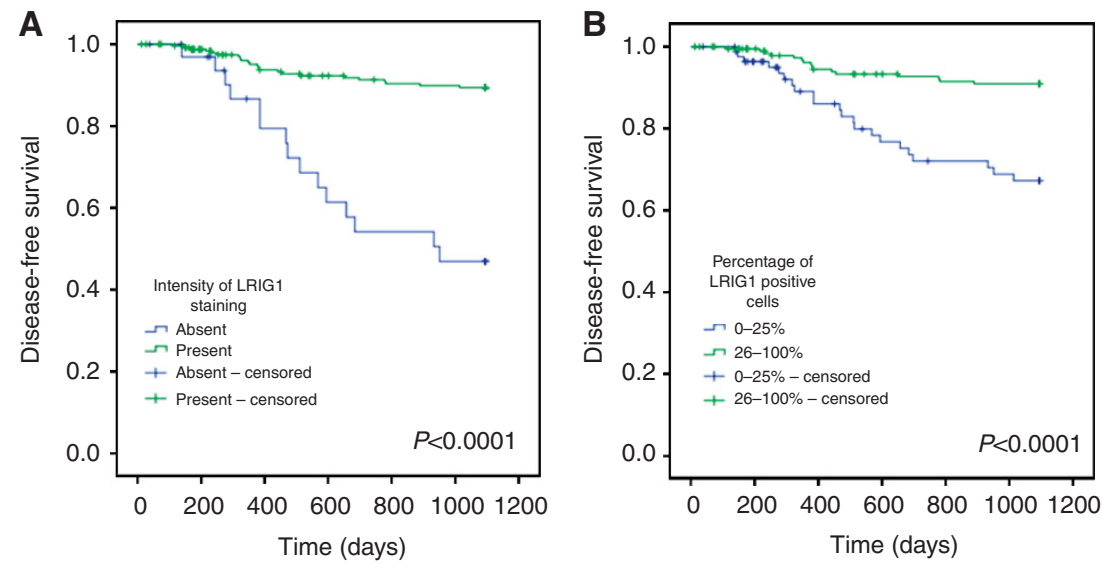

Figure 2. Disease-free survival of 278 oropharyngeal cancer patients. Kaplan-Meier curves according to LRIG1 staining intensity (A) and the percentage of LRIG1-positive cells (B) ( $P$-values of each graph shown in the figure, log-rank test).
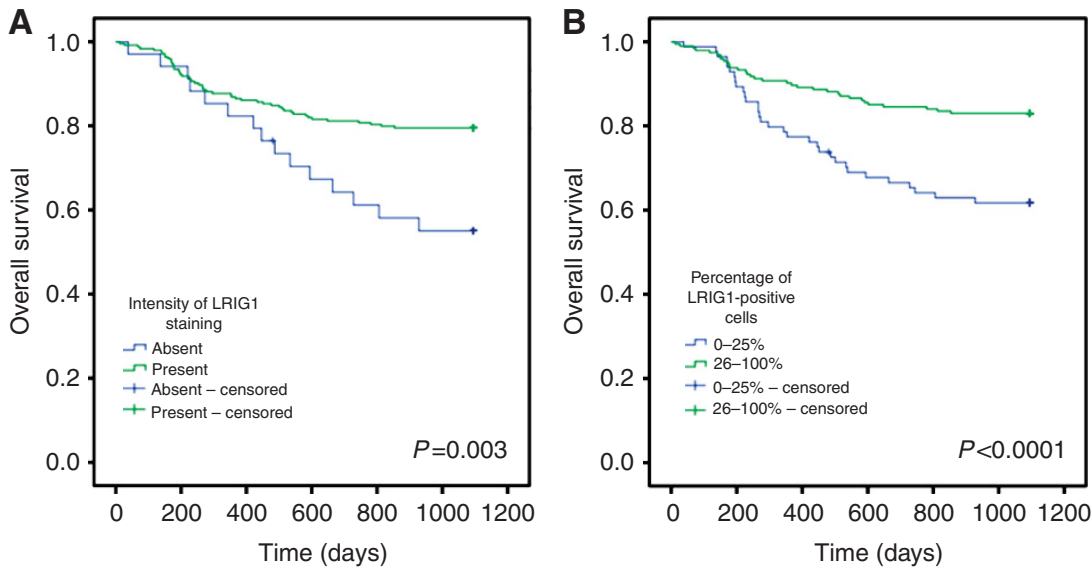

Figure 3. Overall survival of 278 oropharyngeal cancer patients. Kaplan-Meier curves according to LRIG1 staining intensity (A) and percentage of LRIG1-positive cells (B) ( $P$-values of each graph shown in the figure, log-rank test).

(Figures 2 and 3). Similarly, Cox regression univariate analyses showed correlations between disease-free and overall survival and intensity of LRIG1 staining $(P<0.0001$, HR $0.17,0.086-0.32,95 \%$ $\mathrm{CI}$ and $P=0.004$, HR $0.43,95 \%$ CI $0.24-0.76$, respectively) and the percentage of LRIG1-positive cells $(P<0.0001$, HR $0.25,95 \%$ CI $0.13-0.48$ and $P<0.0001$, HR $0.40,95 \%$ CI $0.24-0.65$, respectively). LRIG1 expression and known prognostic factors, including HPV status, CD44 immunostaining intensity, patient age, tumour stage, sex, and localisation, were then included in multivariate Cox proportional regression models to evaluate the independence of each marker. These analyses revealed that both the intensity of LRIG1 staining (Table 2) and the percentage of cells positive for LRIG1 (Table 3) were independent prognostic indicators of both disease-free survival and overall survival.

Next, we stratified the patients according to the HPV status of their tumours and performed univariate and multivariate analyses as previously described. For patients with HPV-positive tumours (215 patients and 32 deaths), both LRIG1 staining intensity and the percentage of LRIG1-positive cells remained independent prognostic markers for disease-free survival (Figure $4 \mathrm{~A}$ and $\mathrm{B}$, $P<0.0001$ and $P<0.0001$, respectively). A Cox regression univariate analysis was performed for the intensity of LRIG1 staining $(P<0.0001$, HR $0.17,95 \%$ CI $0.086-0.32)$ and for the percentage of cells positive for LRIG1 $(P<0.0001$, HR $0.25,95 \%$ CI 0.13-0.48). For the HPV-negative tumours (63 patients and 33 deaths), no correlation was observed between LRIG1 staining intensity or the percentage of LRIG1-positive cells and disease-free survival (Figure $4 \mathrm{C}$ and $\mathrm{D}, P=0.575$ and $P=0.484$, respectively). When the same analysis was performed for overall survival, LRIG1 staining intensity and the percentage of LRIG1-positive cells correlated with survival in the patients with HPV-positive tumours but not in the patients with HPV-negative tumours (graph not shown). When the same multivariate Cox proportional regression model that was performed for all patients was performed including only patients with HPV-positive tumours, both LRIG1 staining intensity and the percentage of LRIG1-positive cells remained statistically significant independent prognostic markers for diseasespecific and overall survival (data not shown).

Neither LRIG2 staining intensity nor the percentage of LRIG2-positive cells correlated with patient survival.

\section{DISCUSSION}

In this study, LRIG1 immunoreactivity was found to be an independent prognostic indicator associated with good survival in HPV-positive tonsillar and base of tongue oropharyngeal cancers. Additionally, the expression of LRIG1 and LRIG2 correlated and inversely correlated, respectively, with HPV status in these tumours. Tonsillar and base of tongue cancers have increased in incidence recently and are often found to be associated with HPV (Hammarstedt et al, 2006; Nasman et al, 2009, 2013; Attner et al, 2010, 2011; Lindquist et al, 2012). Interestingly, the expression of 


\begin{tabular}{|c|c|c|c|c|c|c|}
\hline & \multicolumn{3}{|c|}{ Disease-free survival } & \multicolumn{3}{|c|}{ Overall survival } \\
\hline & $\mathrm{HR}$ & $95 \% \mathrm{Cl}$ & $P$-value & HR & $95 \% \mathrm{Cl}$ & $P$-value \\
\hline \multicolumn{7}{|l|}{ LRIG1 intensity } \\
\hline $\begin{array}{l}\text { Absent } \\
\text { Present }\end{array}$ & $\begin{array}{l}1 \\
0.24\end{array}$ & $\begin{array}{l}\text { (ref) } \\
0.11-0.49\end{array}$ & $<0.0001$ & $\begin{array}{l}1 \\
0.49\end{array}$ & $\begin{array}{l}\text { (ref) } \\
0.26-0.91\end{array}$ & 0.024 \\
\hline \multicolumn{7}{|l|}{ HPV status } \\
\hline $\begin{array}{l}\text { Negative } \\
\text { Positive }\end{array}$ & $\begin{array}{l}1 \\
0.37\end{array}$ & $\begin{array}{l}\text { (ref) } \\
0.18-0.75\end{array}$ & 0.006 & $\begin{array}{l}1 \\
0.26\end{array}$ & $\begin{array}{l}\text { (ref) } \\
0.15-0.43\end{array}$ & $<0.0001$ \\
\hline \multicolumn{7}{|l|}{ CD44 intensity } \\
\hline $\begin{array}{l}\text { Absent/weak } \\
\text { Medium/strong }\end{array}$ & $\begin{array}{l}1 \\
2.88\end{array}$ & $\begin{array}{l}\text { (ref) } \\
0.99-8.37\end{array}$ & 0.052 & $\begin{array}{l}1 \\
2.91\end{array}$ & $\begin{array}{l}\text { (ref) } \\
1.22-6.94\end{array}$ & 0.016 \\
\hline \multicolumn{7}{|l|}{ Age } \\
\hline $\begin{array}{l}>67 \text { years } \\
60-67 \text { years } \\
54-60 \text { years } \\
<54 \text { years }\end{array}$ & $\begin{array}{l}1 \\
0.91 \\
0.58 \\
0.30\end{array}$ & $\begin{array}{l}\text { (ref) } \\
0.41-2.05 \\
0.23-1.45 \\
0.085-1.09\end{array}$ & $\begin{array}{l}0.82 \\
0.25 \\
0.067\end{array}$ & $\begin{array}{l}1 \\
0.64 \\
0.43 \\
0.50\end{array}$ & $\begin{array}{l}\text { (ref) } \\
0.34-1.21 \\
0.21-0.89 \\
0.23-1.09\end{array}$ & $\begin{array}{l}0.17 \\
0.022 \\
0.080\end{array}$ \\
\hline \multicolumn{7}{|l|}{ Stage } \\
\hline $\begin{array}{l}I+I I \\
I I I+I V\end{array}$ & $\begin{array}{l}1 \\
1.41\end{array}$ & $\begin{array}{l}\text { (ref) } \\
0.55-3.63\end{array}$ & 0.48 & $\begin{array}{l}1 \\
2.80\end{array}$ & $\begin{array}{l}\text { (ref) } \\
1.09-7.18\end{array}$ & 0.033 \\
\hline \multicolumn{7}{|l|}{ Sex } \\
\hline $\begin{array}{l}\text { Female } \\
\text { Male }\end{array}$ & $\begin{array}{l}1 \\
1.08\end{array}$ & $\begin{array}{l}\text { (ref) } \\
0.52-2.20\end{array}$ & 0.84 & $\begin{array}{l}1 \\
0.61\end{array}$ & $\begin{array}{l}\text { (ref) } \\
0.33-1.11\end{array}$ & 0.11 \\
\hline \multicolumn{7}{|l|}{ Localisation } \\
\hline $\begin{array}{l}\text { Tonsillar SCC } \\
\text { Base of tongue SCC }\end{array}$ & $\begin{array}{l}1 \\
1.06\end{array}$ & $\begin{array}{l}\text { (ref) } \\
0.20-2.21\end{array}$ & 0.89 & $\begin{array}{l}1 \\
0.88\end{array}$ & $\begin{array}{l}\text { (ref) } \\
0.51-1.52\end{array}$ & 0.65 \\
\hline
\end{tabular}

LRIG1 predicts good survival and correlates with HPV status in cervical adenocarcinoma. Therefore, oropharyngeal cancer is the second HPV-associated cancer type where LRIG1 expression has been found to correlate with patient survival.

Expression of LRIG1 was shown to be an independent marker for better patient survival in multivariate analyses where other known risk factors, such as patient age, tumour stage, and HPV status, were included. LRIG1 expression correlated with HPV status but remained an independent positive prognostic marker in multivariate analyses of patients with HPV-positive tumours. In the HPV-negative group, LRIG1 expression did not correlate with patient survival. However, because of the limited number of HPVnegative cases in the analysed cohort, a possible role of LRIG1 as a prognostic marker in this group cannot be ruled out. Of note, patients with both HPV-positive and LRIG1-positive tumours showed a very good survival outcome. No correlation between LRIG1 expression and tumour stage or patient age was found. Taken together, these results show that the evaluation of LRIG1 expression in tonsillar and base of tongue oropharyngeal cancers may provide further prognostic information in addition to the previously known risk factors.

The expression of LRIG2 did not correlate with survival or any other clinical parameter in our oropharyngeal cancer cohort. This result contrasts with previous results in cervical squamous cell carcinoma, where LRIG2 expression correlates with poor patient survival (Hedman et al, 2010). However, an inverse relationship between LRIG2 expression and HPV status was found in the present study, which has not been reported previously in any HPVassociated cancer. Therefore, the exact role of LRIG2 expression in $\mathrm{HPV}$-associated cancers may warrant further investigation.

Because treatment data were collected retrospectively and were of insufficient quality, it was not possible to evaluate the role of LRIG1 as a predictive factor for specific treatments in this study. However, although treatment was not standardised, most patients received conventional radiotherapy or accelerated radiotherapy combined with surgery depending on the stage of the disease and response to radiotherapy. Chemotherapy was used only in a few cases. Nevertheless, because only patients treated with curative intent were included in the survival analyses, the results may suggest that LRIG1 could be a predictive marker for radiotherapy response. To directly test this hypothesis, a cohort from a clinical trial with patients randomised to defined treatments would be desired.

Previous in vitro studies have shown that LRIG1 may increase the sensitivity of bladder, glioma, and oesophageal cancer cells to platinum-based drugs (Stutz et al, 2008; Li et al, 2011; Wu et al, 2011). Platinum-based therapy is frequently used in the palliative setting in oropharyngeal cancer; therefore, the predictive value of LRIG1 in this setting may warrant further investigation. In the curative setting, two concomitant drugs are now available for the treatment of oropharyngeal cancer: either cisplatin (Pignon et al, 2009) or the EFGR antagonist cetuximab (Bonner et al, 2010) may 
Table 3. Cox regression multivariate analysis including the percentage of LRIG1-positive cells and known prognostic factors for patients with oropharyngeal cancer

\begin{tabular}{|c|c|c|c|c|c|c|}
\hline & \multicolumn{3}{|c|}{ Disease-free survival } & \multicolumn{3}{|c|}{ Overall survival } \\
\hline & HR & $95 \% \mathrm{Cl}$ & $P$-value & HR & $95 \% \mathrm{Cl}$ & $P$-value \\
\hline \multicolumn{7}{|l|}{ LRIG1 expression } \\
\hline $\begin{array}{l}0-25 \% \\
26-100 \%\end{array}$ & $\begin{array}{l}1 \\
0.33\end{array}$ & $\begin{array}{l}\text { (ref) } \\
0.17-0.65\end{array}$ & 0.001 & $\begin{array}{l}1 \\
0.49\end{array}$ & $\begin{array}{l}\text { (ref) } \\
0.30-0.82\end{array}$ & 0.006 \\
\hline \multicolumn{7}{|l|}{ HPV status } \\
\hline $\begin{array}{l}\text { Negative } \\
\text { Positive }\end{array}$ & $\begin{array}{l}1 \\
0.34\end{array}$ & $\begin{array}{l}\text { (ref) } \\
0.17-0.69\end{array}$ & 0.003 & $\begin{array}{l}1 \\
0.27\end{array}$ & $\begin{array}{l}\text { (ref) } \\
0.16-0.45\end{array}$ & $<0.0001$ \\
\hline \multicolumn{7}{|l|}{ CD44 intensity } \\
\hline $\begin{array}{l}\text { Absent/weak } \\
\text { Medium/strong }\end{array}$ & $\begin{array}{l}1 \\
2.81\end{array}$ & $\begin{array}{l}(\text { ref) } \\
0.97-8.15\end{array}$ & 0.057 & $\begin{array}{l}1 \\
2.96\end{array}$ & $\begin{array}{l}\text { (ref) } \\
1.24-7.02\end{array}$ & 0.014 \\
\hline \multicolumn{7}{|l|}{ Age } \\
\hline $\begin{array}{l}>67 \text { years } \\
60-67 \text { years } \\
54-60 \text { years } \\
<54 \text { years }\end{array}$ & $\begin{array}{l}1 \\
1.02 \\
0.57 \\
0.29\end{array}$ & $\begin{array}{l}\text { (ref) } \\
0.46-2.27 \\
0.22-1.41 \\
0.082-1.05\end{array}$ & $\begin{array}{l}0.96 \\
0.22 \\
0.59\end{array}$ & $\begin{array}{l}1 \\
0.67 \\
0.43 \\
0.50\end{array}$ & $\begin{array}{l}\text { (ref) } \\
0.37-1.24 \\
0.21-0.88 \\
0.23-1.09\end{array}$ & $\begin{array}{l}0.203 \\
0.020 \\
0.082\end{array}$ \\
\hline \multicolumn{7}{|l|}{ Stage } \\
\hline $\begin{array}{l}I+I I \\
I I I+I V\end{array}$ & $\begin{array}{l}1 \\
1.29\end{array}$ & $\begin{array}{l}\text { (ref) } \\
0.50-3.33\end{array}$ & 0.59 & $\begin{array}{l}1 \\
2.6\end{array}$ & $\begin{array}{l}\text { (ref) } \\
1.02-6.72\end{array}$ & 0.045 \\
\hline \multicolumn{7}{|l|}{ Sex } \\
\hline $\begin{array}{l}\text { Female } \\
\text { Male }\end{array}$ & $\begin{array}{l}1 \\
1.05\end{array}$ & $\begin{array}{l}\text { (ref) } \\
0.51-2.15\end{array}$ & 0.90 & $\begin{array}{l}1 \\
0.62\end{array}$ & $\begin{array}{l}\text { (ref) } \\
0.34-1.15\end{array}$ & 0.13 \\
\hline \multicolumn{7}{|l|}{ Localisation } \\
\hline $\begin{array}{l}\text { Tonsillar SCC } \\
\text { Base of tongue SCC }\end{array}$ & $\begin{array}{l}1 \\
1.29\end{array}$ & $\begin{array}{l}\text { (ref) } \\
0.62-2.68\end{array}$ & 0.50 & $\begin{array}{l}1 \\
0.99\end{array}$ & $\begin{array}{l}\text { (ref) } \\
0.58-1.71\end{array}$ & 0.98 \\
\hline
\end{tabular}

be used in parallel with radiotherapy. If LRIG1 expression turns out to be a predictive marker for treatment with platinum-based drugs or cetuximab, analysing LRIG1 expression may aid in clinical decision-making regarding the choice of whether concomitant cisplatin or cetuximab may be beneficial for the patient.

LRIG1 inhibits tyrosine kinase receptors and functions as a tumour suppressor. Furthermore, it has been shown that LRIG1 ectodomains can be shed and suppress EGF signalling and cancer cell proliferation in a paracrine manner (Yi et al, 2011; Johansson et al, 2013). Moreover, deletions of chromosome $3 \mathrm{p}$, including the LRIG1 locus at 3p14, are frequent events in head and neck cancers, and in vitro experiments have shown that LRIG1 regulates both cell proliferation and growth factor signalling in nasopharyngeal cancer cell lines (Sheu et al, 2014). It will therefore be important to investigate the molecular and biological function of LRIG1 in tonsillar and base of tongue cancers.

The staining pattern of LRIG1 in this cohort was exclusively nuclear. The LRIG proteins show cell-type-specific differences in their subcellular localisation (Hedman and Henriksson, 2007). For example, in astrocytoma, LRIG1 staining is nuclear, perinuclear, and cytoplasmic, and perinuclear staining correlates with low WHO grade (Guo et al, 2006). In normal skin, nuclear LRIG1 expression is frequently observed; however, in psoriatic skin, LRIG1 is redistributed to the cytoplasm and only rarely seen in cell nuclei (Karlsson et al, 2008). Thus, the subcellular distribution of LRIG1 seems to vary, and the role of the nuclear LRIG1 staining pattern found in oropharyngeal cancer remains unknown.

In conclusion, LRIG1 immunoreactivity was found to be an independent positive prognostic marker that correlates with HPV status in tonsillar and base of tongue cancers. Furthermore, in patients with HPV-positive tumours, the evaluation of LRIG1 offered added prognostic information. Therefore, the role of the LRIG proteins in oropharyngeal cancer and other cancers known to be associated with HPV warrants further investigation.

\section{ACKNOWLEDGEMENTS}

We thank Ulla-Stina Spetz for help with the LRIG immunostainings. We are also grateful for financial support from the Swedish Cancer Society, the Stockholm Cancer Society, the Swedish Research Council, the Karolinska Institute, the Cancer Research Foundation in Northern Sweden, the F Olaison Foundation, and I and H Perssons Foundation, Swedish Society for Medical Research, the Center for Clinical Research Dalarna, and through the regional agreement between Umeå University and Västerbotten County Council on cooperation in the field of Medicine, Odontology 

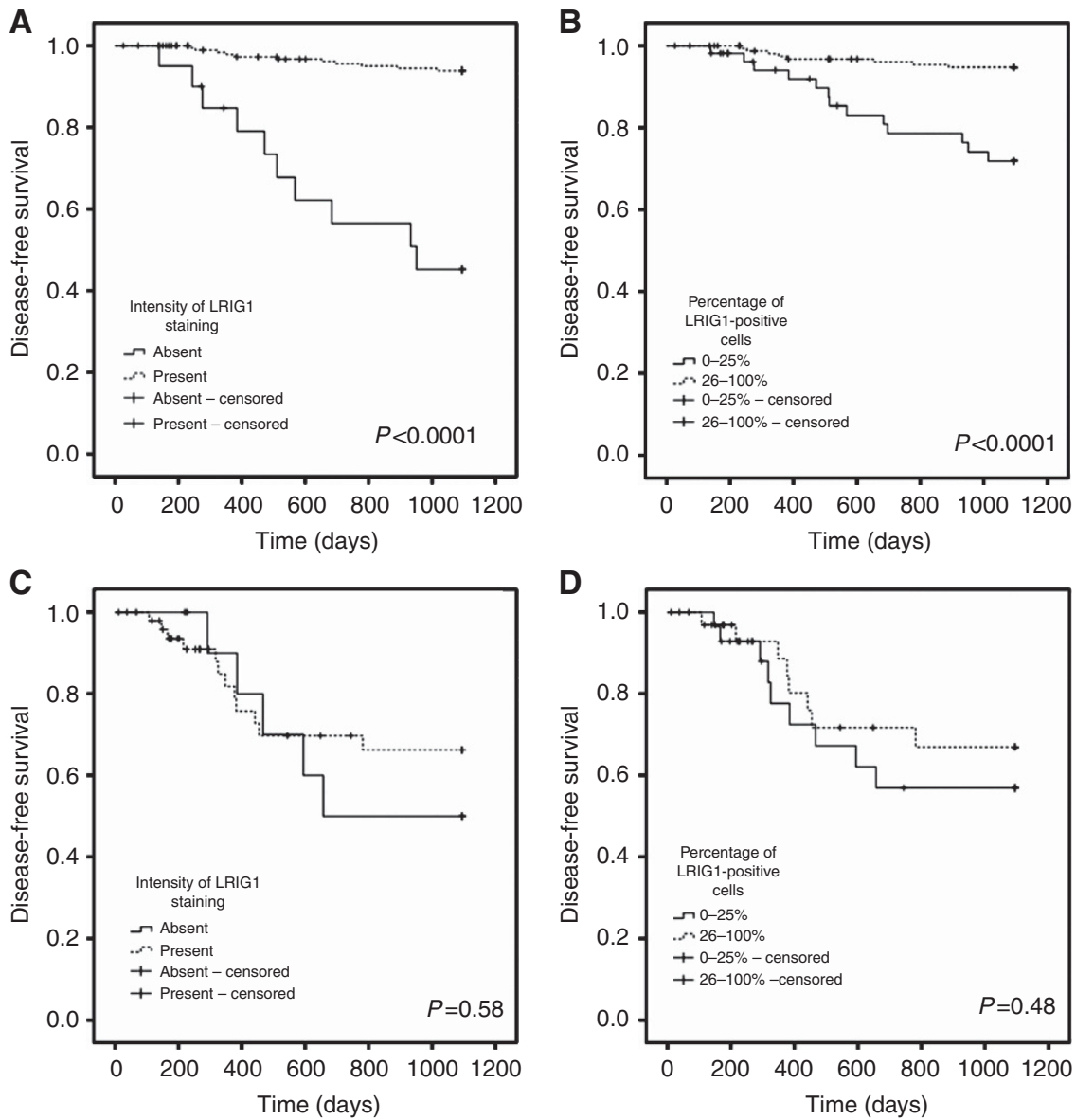

Figure 4. Disease-free survival of 278 oropharyngeal cancer patients according to HPV status and LRIG1 staining intensity or percentage of LRIG1-positive cells of their tumours. (A, B) Kaplan-Meier curves for HPV-positive tumours according to LRIG1 staining intensity (A) and the percentage of LRIG1-positive cells (B). (C, D) HPV-negative tumours according to LRIG1 staining intensity (C) and percentage of LRIG1-positive cells (D).

and Health. The funding sources had no involvement in any part of the study.

\section{REFERENCES}

Attner P, Du J, Nasman A, Hammarstedt L, Ramqvist T, Lindholm J, Marklund L, Dalianis T, Munck-Wikland E (2010) The role of human papillomavirus in the increased incidence of base of tongue cancer. Int J Cancer 126: 2879-2884.

Attner P, Du J, Nasman A, Hammarstedt L, Ramqvist T, Lindholm J, Marklund L, Dalianis T, Munck-Wikland E (2011) Human papillomavirus and survival in patients with base of tongue cancer. Int J Cancer 128: 2892-2897.

Bonner JA, Harari PM, Giralt J (2010) Radiotherapy plus cetuximab for locoregionally advanced head and neck cancer: 5 -year survival data from a phase 3 randomised trial, and relation between cetuximab-induced rash and survival. Lancet Oncol 11: 21-28.

Ferlay J, Shin HR, Bray F, Forman D, Mathers C, Parkin DM (2010) Estimates of worldwide burden of cancer in 2008: GLOBOCAN 2008. Int J Cancer 127: 2893-2917.

Guo D, Holmlund C, Henriksson R, Hedman H (2004) The LRIG gene family has three vertebrate paralogs widely expressed in human and mouse tissues and a homolog in Ascidiacea. Genomics 84: 157-165.

Guo D, Nilsson J, Haapasalo H, Raheem O, Bergenheim T, Hedman H, Henriksson R (2006) Perinuclear leucine-rich repeats and immunoglobulin-like domain proteins (LRIG1-3) as prognostic indicators in astrocytic tumors. Acta Neuropathol 111: 238-246.

Gur G, Rubin C, Katz M, Amit I, Citri A, Nilsson J, Amariglio N, Henriksson R, Rechavi G, Hedman H, Wides R, Yarden Y (2004) LRIG1 restricts growth factor signaling by enhancing receptor ubiquitylation and degradation. EMBO J 23: 3270-3281.

Hammarstedt L, Lindquist D, Dahlstrand H, Romanitan M, Dahlgren LO, Joneberg J, Creson N, Lindholm J, Ye W, Dalianis T, Munck-Wikland E (2006) Human papillomavirus as a risk factor for the increase in incidence of tonsillar cancer. Int J Cancer 119: 2620-2623.

Hedman H, Henriksson R (2007) LRIG inhibitors of growth factor signalling - double-edged swords in human cancer? Eur J Cancer 43 676-682.

Hedman H, Lindstrom AK, Tot T, Stendahl U, Henriksson R, Hellberg D (2010) LRIG2 in contrast to LRIG1 predicts poor survival in early-stage squamous cell carcinoma of the uterine cervix. Acta Oncol 49: 812-815.

Holmlund C, Nilsson J, Guo D, Starefeldt A, Golovleva I, Henriksson R, Hedman H (2004) Characterization and tissue-specific expression of human LRIG2. Gene 332: 35-43.

Johansson M, Oudin A, Tiemann K, Bernard A, Golebiewska A, Keunen O, Fack F, Stieber D, Wang B, Hedman H, Niclou SP (2013) The soluble form of the tumor suppressor Lrigl potently inhibits in vivo glioma growth irrespective of EGF receptor status. Neuro Oncol 15(9): 1200-1211.

Karlsson T, Mark EB, Henriksson R, Hedman H (2008) Redistribution of LRIG proteins in psoriasis. J Invest Dermatol 128: 1192-1195.

Krig SR, Frietze S, Simion C, Miller JK, Fry WH, Rafidi H, Kotelawala L, Qi L, Griffith OL, Gray JW, Carraway 3rd KL, Sweeney C (2011) Lrig1 is an estrogen-regulated growth suppressor and correlates with longer relapse-free survival in ERalpha-positive breast cancer. Mol Cancer Res 9: $1406-1417$.

Laederich MB, Funes-Duran M, Yen L, Ingalla E, Wu X, Carraway 3rd KL, Sweeney C (2004) The leucine-rich repeat protein LRIG1 is a negative regulator of ErbB family receptor tyrosine kinases. J Biol Chem 279: 47050-47056. 
Ledda F, Bieraugel O, Fard SS, Vilar M, Paratcha G (2008) Lrig1 is an endogenous inhibitor of Ret receptor tyrosine kinase activation, downstream signaling, and biological responses to GDNF. J Neurosci 28: 39-49.

Li F, Yang W, Guo D, Hu Z, Xu H, Ye Z (2011) LRIG1 combined with cisplatin enhances bladder cancer lesions via a novel pathway. Oncol Rep 25: 1629-1637.

Lindquist D, Ahrlund-Richter A, Tarjan M, Tot T, Dalianis T (2012) Intense CD44 expression is a negative prognostic factor in tonsillar and base of tongue cancer. Anticancer Res 32: 153-161.

Lindstrom AK, Ekman K, Stendahl U, Tot T, Henriksson R, Hedman H, Hellberg D (2008) LRIG1 and squamous epithelial uterine cervical cancer: correlation to prognosis, other tumor markers, sex steroid hormones, and smoking. Int J Gynecol Cancer 18: 312-317.

Lindstrom AK, Stendahl U, Tot T, Hellberg D (2007) Associations between ten biological tumor markers in squamous cell cervical cancer and serum estradiol, serum progesterone and smoking. Anticancer Res 27: 1401-1406.

Mellin H, Dahlgren L, Munck-Wikland E, Lindholm J, Rabbani H, Kalantari M, Dalianis T (2002) Human papillomavirus type 16 is episomal and a high viral load may be correlated to better prognosis in tonsillar cancer. Int $J$ Cancer 102: 152-158.

Mellin HD, Munck-Wikland E, Dahlgren L, Dalianis T (2004) [Occurrence of human papillomavirus is a positive factor in tonsillar cancer. Reduced risk of recurrence and longer survival]. Lakartidningen 101: 2794-27962798.

Muller S, Lindquist D, Kanter L, Flores-Staino C, Henriksson R, Hedman H, Andersson S (2013) Expression of LRIG1 and LRIG3 correlates with human papillomavirus status and patient survival in cervical adenocarcinoma. Int J Oncol 42: 247-252.

Nasman A, Attner P, Hammarstedt L, Du J, Eriksson M, Giraud G, Ahrlund-Richter S, Marklund L, Romanitan M, Lindquist D, Ramqvist T, Lindholm J, Sparen P, Ye W, Dahlstrand H, Munck-Wikland E, Dalianis T (2009) Incidence of human papillomavirus (HPV) positive tonsillar carcinoma in Stockholm, Sweden: an epidemic of viral-induced carcinoma? Int J Cancer 125: 362-366.

Nasman A, Nordfors C, Grun N, Munck-Wikland E, Ramqvist T, Marklund L, Lindquist D, Dalianis T (2013) Absent/low CD44 intensity and positive human papillomavirus (HPV) status in oropharyngeal squamous cell carcinoma indicates a very high survival. Cancer Med 2(4): 507-518.

Nilsson J, Starefeldt A, Henriksson R, Hedman H (2003) LRIG1 protein in human cells and tissues. Cell Tissue Res 312: 65-71.

Nilsson J, Vallbo C, Guo D, Golovleva I, Hallberg B, Henriksson R, Hedman H (2001) Cloning, characterization, and expression of human LIG1. Biochem Biophys Res Commun 284: 1155-1161.
Pignon JP, Le Maitre A, Maillard E, Bourhis J (2009) Meta-analysis of chemotherapy in head and neck cancer (MACH-NC): an update on 93 randomised trials and 17,346 patients. Radiother Oncol 92: 4-14.

Powell AE, Wang Y, Li YN, Poulin EJ, Means AL, Washington MK, Higginbotham JN, Juchheim A, Prasad N, Levy SE, Guo Y, Shyr Y, Aronow BJ, Haigis KM, Franklin JL, Coffey RJ (2012) The Pan-ErbB negative regulator lrig1 is an intestinal stem cell marker that functions as a tumor suppressor. Cell 149: 146-158.

Ramqvist T, Dalianis T (2010) Oropharyngeal cancer epidemic and human papillomavirus. Emerg Infect Dis 16: 1671-1677.

Shattuck DL, Miller JK, Laederich M, Funes M, Petersen H, Carraway 3rd KL, Sweeney C (2007) LRIG1 is a novel negative regulator of the Met receptor and opposes Met and Her2 synergy. Mol Cell Biol 27: 1934-1946.

Sheu JJ, Lee CC, Hua CH, Li CI, Lai MT, Lee SC, Cheng J, Chen CM, Chan C, Chao SC, Chen JY, Chang JY, Lee CH (2014) LRIG1 modulates aggressiveness of head and neck cancers by regulating EGFR-MAPKSPHK1 signaling and extracellular matrix remodeling. Oncogene 33(11): 1375-1384.

Stutz MA, Shattuck DL, Laederich MB, Carraway 3rd KL, Sweeney C (2008) LRIG1 negatively regulates the oncogenic EGF receptor mutant EGFRvIII. Oncogene 27: 5741-5752.

Tanemura A, Nagasawa T, Inui S, Itami S (2005) LRIG-1 provides a novel prognostic predictor in squamous cell carcinoma of the skin: immunohistochemical analysis for 38 cases. Dermatol Surg 31: 423-430.

Thomasson M, Wang BF, Hammarsten P, Dahlman A, Persson JL, Josefsson A, Stattin P, Granfors T, Egevad L, Henriksson R, Bergh A, Hedman H (2011) LRIG1 and the liar paradox in prostate cancer: a study of the expression and clinical significance of LRIG1 in prostate cancer. Int J Cancer 128: 2843-2852.

Wang Y, Poulin E, Coffey R (2013) LRIG1 is a triple threat: ERBB negative regulator, intestinal stem cell marker and tumour suppressor. $\mathrm{Br} J$ Cancer 108: $1765-1770$.

Wu X, Hedman H, Bergqvist M, Bergstrom S, Henriksson R, Gullbo J, Lennartsson J, Hesselius P, Ekman S (2011) Expression of EGFR and LRIG proteins in oesophageal carcinoma with emphasis on patient survival and cellular chemosensitivity. Acta Oncol 51(1): 69-76.

Yi W, Holmlund C, Nilsson J, Inui S, Lei T, Itami S, Henriksson R, Hedman H (2011) Paracrine regulation of growth factor signaling by shed leucine-rich repeats and immunoglobulin-like domains 1. Exp Cell Res 317: 504-512.

This work is published under the standard license to publish agreement. After 12 months the work will become freely available and the license terms will switch to a Creative Commons AttributionNonCommercial-Share Alike 3.0 Unported License.

Supplementary Information accompanies this paper on British Journal of Cancer website (http://www.nature.com/bjc) 